\title{
A New Approach to an Old Problem: Controversial Issues in Seasonal Rhinoconjunctivitis
}

\section{Fuat Kalyoncu A*}

Division of Allergy and Immunology, Department of Chest Diseases, Hacettepe University School of Medicine, Turkey

Keywords: Allergic rhinitis; Intermittent rhinitis; Immunotherapy; Pollen allergy; Pollen food allergy; Seasonal allergic rhinitis; Skin prick test

\section{Introduction}

Pollen allergy is common in many parts of the world and the prevalence of seasonal allergic rhinitis (SR) is reported to be upto $40 \%$ [1]. Allergic rhinitis (AR) causes significant morbidity and is an important cause of presentation to otorhinolaryngology, pulmonology, internal medicine, pediatrics, and primary care clinics. It is one of the three most common consultation reason in pediatric and adult allergy clinics [2]. The diagnosis and treatment of AR is based on ARIA guidelines, and national and/or occupational organizations' consensus reports [3]. Recently, the Turkish National Society of Allergy and Clinical Immunology published a consensus report on the diagnosis and treatment of AR [4].

The treatment of AR consists of regular use of anti-inflammatory medications, avoidance of triggers, and symptomatic treatment, as needed. When indicated, specific immunotherapy can also be considered. SR is a sub-group of AR. SR can manifest in isolation, or numerous allergic and/or non-allergic comorbidities can accompany it, which sometimes determine the choice of treatment and indicate the prognosis. We think that the recently used terms persistent and intermittent can not fully replace the term seasonal. SR can both be persistent and intermittent; the terms persistent and intermittent may be directive for physicians other than allergists.

Generally, the term persistent is not prognostic, whereas SR is usually considered to be a pure IgE-mediated, benign, and self-limited disease [5]. It was reported that SR is a disease of young generation, and that the incidence of spontaneous remission or a decrease in SR symptoms increases with age [5]. SR disease activity is closely related to air pollen levels, which are affected by mean annual rainfall. That fluctuations in pollen level cause clinical differences in disease activity between years, even in some years SR may be considered as in remission. Travelling during pollen season can affect the severity of symptoms. Genetic and environmental factors, and smoking can lead to persistent symptoms.

\section{Special Considerations in the Diagnosis and Treatment of SR, and Risk Analysis of Comorbidities as Asthma}

The diagnosis of SR is based on clinical history. Skin prick testing should be performed when specific immunotherapy is considered, for academic purposes, to determine the risk of comorbidity, and to increase treatment compliance. Several studies have shown that a considerable number of patients with negative skin prick test responses, negative intradermal skin test results, and lack of serum specific IgE that would otherwise have been diagnosed as non-allergic rhinitis have nasal symptoms following nasal allergen provocation testing performed with common aeroallergens, including house dust mites, and grass and olive pollen, and that such patients are diagnosed as local allergic rhinitis [6]. It is possible that $47 \%-62.5 \%$ of patients with perennial and seasonal allergy symptoms have local allergic rhinitis [6].
Anamnesis should include detailed information about the duration of symptoms, duration of daily outdoor activities, occupational environment, and place of residence (urban/rural). Rare pollens may cause symptoms $[7,8]$. Symptoms are generally less severe in coastal regions, change in place of residence in the same country or immigration should be asked. The sensitizing allergens in atopic immigrants may in time resemble those in native inhabitants of a particular region [911]. Change in place of residence in the same country also may cause a change in sensitized allergen spectrum.

History of sigarette smoking should be noted when evaluating the severity of rhinitis and the presence of the symptoms of asthma. The presence of risk factors for the development of comorbidities should be evaluated. Herein a classification system that can be used to evaluate comorbidities in patients with pollen-allergic SR is proposed (Figure 1). Asthma, eczema/urticaria, and food hypersensitivity can be comorbid with SR or can occur in the absence of the symptoms of SR in pollen allergy.

A standardized questionnaire for evaluating comorbidity in SR patients is lacking. Table 1 is an example of a questionnaire that could be used to determine the risk of comorbidity. We are currently conducting research on this issue. We previously published 4 studies on comorbidities and/or the risk factors for comorbidity in SR patients [11-14].

We reported that among 774 anamnesis-compatible SR patients, $14 \%, 13.4 \%$, and $9.6 \%$ had food hypersensitivity, bronchial asthma, and drug allergy and/or intolerance, respectively. The use of specific immunotherapy and short-acting antihistamines decreased over time, whereas the use of nasal steroids, and long-acting antihistamines increased. Familial atopy, the presence of respiratory and/or ocular symptoms, and metal allergy were associated with asthma [11].

In addition, 922 anamnesis-compatible SR patients were grouped as non-sensitized to any allergen, sensitized to only 1 pollen allergen, sensitized to $>1$ pollen allergen, and sensitized to mites, with or without allergen sensitization. The group with no sensitization and mite sensitization had the highest prevalence of asthma, whereas the monopollen-sensitized group was unlikely to have an accompanying allergic disease [12].

*Corresponding author: Fuat Kalyoncu A, Division of Allergy and Immunology Department of Chest Diseases, Hacettepe University School of Medicine, 06100 Sihhiye, Ankara, Turkey, Tel: +90312 3051721; Fax: +90312 3053096; E-mail: kalyon@ada.net.tr

Received February 01, 2014; Accepted February 23, 2014; Published February 27,2014

Citation: Fuat Kalyoncu A (2014) A New Approach to an Old Problem: Controversia Issues in Seasonal Rhinoconjunctivitis. J Allergy Ther 5: 164. doi:10.4172/21556121.1000164

Copyright: (c) 2014 Fuat Kalyoncu A. This is an open-access article distributed under the terms of the Creative Commons Attribution License, which permits unrestricted use, distribution, and reproduction in any medium, provided the original author and source are credited. 


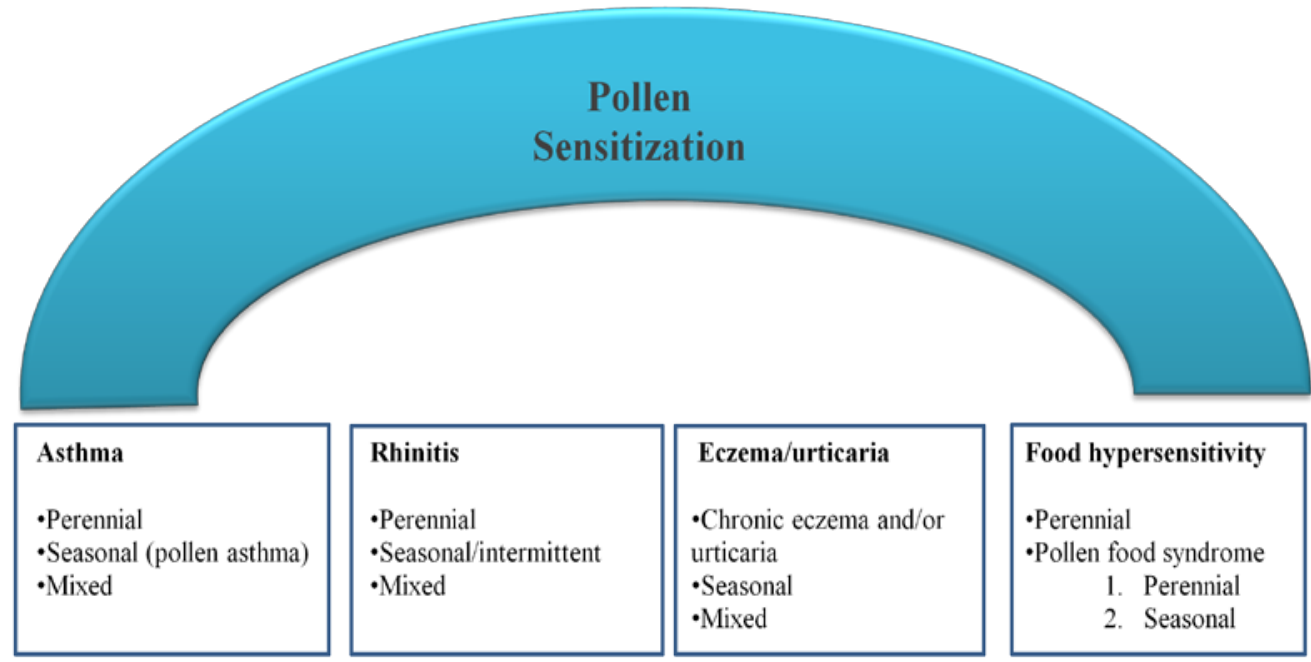

Figure 1: Comorbidities/phenotypes of pollen allergy ( $\pm S R)$.

\begin{tabular}{|l|l|l|}
\hline & Yes & No \\
\hline History of cigarette smoking & $\mathrm{O}$ & $\mathrm{O}$ \\
\hline Coughing/wheezing/dyspnea and/or susceptibility to odors & $\mathrm{O}$ & $\mathrm{O}$ \\
\hline Seasonal symptoms with negative skin prick/splgE test & $\mathrm{O}$ & $\mathrm{O}$ \\
\hline Mite sensitization with or without pollen sensitization & $\mathrm{O}$ & $\mathrm{O}$ \\
\hline Little or no nasal hair & $\mathrm{O}$ & $\mathrm{O}$ \\
\hline Outdoor occupation & $\mathrm{O}$ & $\mathrm{O}$ \\
\hline Daily outdoor activity $>1$ hour & $\mathrm{O}$ & $\mathrm{O}$ \\
\hline Metal allergy & $\mathrm{O}$ & $\mathrm{O}$ \\
\hline
\end{tabular}

*yes to $\geq 1$ item may be associated with an increased risk of asthma

Table 1: A questionnaire that could be used to determine the risk of asthma in patients with $\mathrm{SR}^{*}$

In another study the severity of asthma in patients with analgesic intolerance, SR, and chronic urticaria was analyzed. Asthmatic patients with SR had significantly milder and earlier onset asthma, better pulmonary function test results, and were significantly more atopic, whereas asthma in the analgesic-intolerant patients was more severe, and asthma in the chronic urticaria patients did not exhibit a specific phenotypic characteristic [13].

Nasal hairs are often unwanted due to cosmetic concerns and, as such many people are in the habit of cutting them. Removal or absence of nasal hair could be a risk for the development of asthma. Our fourth study reported that asthma is more common in patients with few nasal hairs, whereas the presence of many nasal hairs protected against the risk of developing asthma in SR patients [14].

\section{Risk Analysis for Food Allergy}

More than $70 \%$ of birch-pollen-allergic patients suffer from an oral allergy syndrome (OAS) to fruits and/or nuts, that is based on a molecular similarity of their major allergens leading to clinical crossreactivity [15].

The presence of dermatological symptoms, duration of rhinitis $>5$ years and duration of symptoms $>3$ months/per year, sensitization to Artemisia vulgaris and/or tree pollen (Corylus avellena, Betula verrucosa) allergens, and the presence of bee allergy are risk factors for the development of food hypersensitivity in patients with SR [16].

Consuming honey and honey products (propolis, royal jelly) can lead to allergic reactions, as well as anaphylaxis, diarrhea, and abdominal pain $[17,18]$. It is reported that patients complain of abdominal pain more frequently than allergy symptoms. Patients should be investigated for the presence of OAS and diagnostic evaluation should be performed when appropriate.

\section{Special Treatment Considerations}

SR can be treated at primary care centers; however, an allergy consultation is needed to evaluate the presence of and risk factors for comorbidity, failure of standard treatment when specific immunotherapy is considered. Clinicians must be aware that the number and type of sensitized allergens can change with time [19].

Allergen avoidance is difficult for patients with pollen allergy; patients must make lifestyle changes. Outdoor activities should be limited during pollen season. To reduce the pollen count inside home and work environments, patients must keep windows and other unfiltered openings closed. Wearing sunglasses outdoors can protect against pollens [20]. Special sunglasses designed to protect eyes from pollen exposure in outdoor environments may be routinely recommended to pollen-allergic patients [20]. We are currently conducting a prospective study on the protective efficiency of a specially designed eyeglass. Patients should frequently wash their eyes and face, and/or shower. It is known that nasal vibrissae density affects the risk of development of asthma in patients with SR. Patients with SR should not cut their nasal hair during pollen season. Beards, moustaches, and long hair probably attract more pollen during daily activities; however, it is not known if they have a protective effect. Clinicians should always remember that preventive care is always less expensive than medical treatment.

Nasal steroids are the first-line treatment option for AR; other treatment options include second-generation antihistamines, topical $\mathrm{H} 1$ antihistamines, and leucotrien receptor antagonists. The efficacy of prophylactic treatment with antihistamines before the start of pollen season for prevention of aggravation of symptoms was examined, and it was found that early intervention with levosetirizine soon after onset of symptoms was as effective as prophylactic treatment before pollen season [21]. Regular use of nasal steroids is needed during pollen season, and allergen avoidance strategies can theoretically decrease the need for antihistamine tablets and eye drops. If standard treatment is ineffective 
Citation: Fuat Kalyoncu A (2014) A New Approach to an Old Problem: Controversial Issues in Seasonal Rhinoconjunctivitis. J Allergy Ther 5: 164. doi:10.4172/2155-6121.1000164

to control symptoms, patients may benefit from short-course oral or systemic corticosteroids [22]. However, treating SR with depo-steroid injections should be abondoned as it is associated with increased risk of diabetes and osteoporosis [23]. Perennial or preseasonal subcutaneous, sublingual, oral or intralymphatic allergen-specific immunotherapy can be another treatment option in carefully selected patients [24-26].

In fact, many physicians recommend and/or patients prefer nose washing with tap water or isotonic saline (due to personal hygiene reasons, obsession, religious beliefs); washing the nose with tap water may be hazardous, whereas use of isotonic or hypertonic saline is reported to be controversial [27]. However, a recent meta-analysis reported that saline nasal irrigation using isotonic solution can be recommended as a complementary therapy in allergic rhinitis as it is well tolerated, inexpensive, easy to use, and there is no evidence showing that regular, daily saline nasal irrigation adversely affects the patient's health and or causes unexpected side effects [28].

\section{Ethical Disclosures}

The author declares that no patient data appears in this article. No experiments were performed on humans or animals for this investigation. The author for correspondence is in possession of this document (AFK). The procedures followed were in accordance with the regulations of the responsible Clinical Research Ethics Committee and in accordance with those of the World Medical Association and the Helsinki Declaration.

\section{References}

1. Bousquet J, Khaltaev N, Cruz AA, Denburg J, Fokkens WJ, et al. (2008) Allergic Rhinitis and its Impact on Asthma (ARIA) 2008 update (in collaboration with the World Health Organization, GA(2)LEN and AllerGen). Allergy 63: 8-160.

2. England RW, Ho TC, Napoli DC, Quinn JM (2003) Inpatient consultation of allergy/immunology in a tertiary care setting. Ann Allergy Asthma Immunol 90: 393-397

3. Bousquet J, Schünemann HJ, Samolinski B, Demoly $P$, Baena-Cagnani $C E$ et al. (2012) World Health Organization Collaborating Center for Asthma and Rhinitis. Allergic Rhinitis and its Impact on Asthma (ARIA): achievements in 10 years and future needs. J Allergy Clin Immunol 130: 1049-1062.

4. Yorgancıoğlu A1, Özdemir C, Kalaycı Ö, Kalyoncu AF, Bachert C, et al. (2012) [ARIA (Allergic Rhinitis and its Impact on Asthma) achievements in 10 years and future needs]. Tuberk Toraks 60: 92-97.

5. Bozkurt B, Karakaya G, Kalyoncu AF (2005) Seasonal rhinitis, clinica characteristics and risk factors for asthma. Int Arch Allergy Immunol 138: 73-79.

6. Rondón C, Campo P, Togias A, Fokkens WJ, Durham SR, et al. (2012) Local allergic rhinitis: concept, pathophysiology, and management. J Allergy Clin Immunol 129: 1460-1467.

7. Demir AU, Karakaya G, Kalyoncu AF (2002) Allergy symptoms and IgE immune response to rose: an occupational and an environmental disease. Allergy 57 936-939.

8. Atis S, Tutluoglu B, Sahin K, Yaman M, Küçükusta AR, et al. (2002) Sensitization to sunflower pollen and lung functions in sunflower processing workers. Allergy 57: 35-39.

9. Kalyoncu AF, Stålenheim G (1992) Serum IgE levels and allergic spectra in immigrants to Sweden. Allergy 47: 277-280.

10. Kalyoncu AF, Stålenheim G (1993) Survey on the allergic status in a Turkish population in Sweden. Allergol Immunopathol (Madr) 21: 11-14.

11. Kalyoncu AF, Demir AU, Kisacik G, Karakoca Y, Iskandarani A, et al. (1995) Birch pollen related food hypersensitivity: as a para-occupational syndrome. Allergol Immunopathol (Madr) 23: 94-95

12. Celikel S, Isik SR, Demir AU, Karakaya G, Kalyoncu AF (2008) Risk factors for asthma and other allergic diseases in seasonal rhinitis. J Asthma 45: 710-714.

13. Celikel S, Isik SR, Demir AU, Karakaya G, Kalyoncu AF (2010) Are chronic urticaria, analgesic intolerance and seasonal rhinitis markers of different severities and phenotypes of the asthma they accompany? Allergol Immunopathol 38: 313-320.

14. Ozturk AB, Damadoglu E, Karakaya G, Kalyoncu AF (2011) Does nasal hair (vibrissae) density affect the risk of developing asthma in patients with seasonal rhinitis? Int Arch Allergy Immunol 156: 75-80.

15. Kopac P, Rudin M, Gentinetta T, Gerber R, Pichler Ch, et al. (2012) Continuous apple consumption induces oral tolerance in birch-pollen-associated apple allergy. Allergy 67 : 280-285.

16. Bozkurt B, Karakaya G, Kalyoncu AF (2005) Food hypersensitivity in patients with seasonal rhinitis in Ankara. Allergol Immunopathol (Madr) 33: 86-92.

17. Kalyoncu AF (1997) Honey allergy and rhinitis in Ankara, Turkey. Allergy 52 876-877

18. Celikel S, Karakaya G, Yurtsever N, Sorkun K, Kalyoncu AF (2006) Bee and bee products allergy in Turkish beekeepers: determination of risk factors for systemic reactions. Allergol Immunopathol (Madr) 34: 180-184.

19. Karakaya G, Kalyoncu AF (2006) The natural course of atopy determined by skin prick tests in patients with bronchial asthma and/or rhinitis. Allergol Immunopathol (Madr) 34: 257-262.

20. Ozturk AB, Celebioglu E, Karakaya G, Kalyoncu AF (2013) Protective efficacy of sunglasses on the conjunctival symptoms of seasonal rhinitis. Int Forum Allergy Rhinol 3: 1001-1006.

21. Yonekura S, Okamoto $Y$, Yamamoto $H$, Sakurai T, linuma $T$, et al. (2013) Randomized double-blind study of prophylactic treatment with an antihistamine for seasonal allergic rhinitis. Int Arch Allergy Immunol 162: 71-78.

22. Karaki M, Akiyama K, Mori N (2013) Efficacy of intranasal steroid spray (mometasone furoate) on treatment of patients with seasonal allergic rhinitis: comparison with oral corticosteroids. Auris Nasus Larynx 40: 277-281.

23. Aasbjerg K, Torp-Pedersen C, Vaag A, Backer V (2013) Treating allergic rhinitis with depot-steroid injections increase risk of osteoporosis and diabetes. Respir Med 107: 1852-1858

24. Tworek D, Bochenska-Marciniak M, Kuprys-Lipinska I, Kupczyk M, Kuna $P$ (2013) Perennial is more effective than preseasonal subcutaneous immunotherapy in the treatment of seasonal allergic rhinoconjunctivitis. Am J Rhinol Allergy 27: 304-308.

25. Dretzke J, Meadows A, Novielli N, Huissoon A, Fry-Smith A, et al. (2013) Subcutaneous and sublingual immunotherapy for seasonal allergic rhinitis: a systematic review and indirect comparison. J Allergy Clin Immunol 131: 13611366.

26. Hylander T, Latif L, Petersson-Westin U, Cardell LO (2013) Intralymphatic allergen-specific immunotherapy: an effective and safe alternative treatment route for pollen-induced allergic rhinitis. J Allergy Clin Immunol 131: 412-420.

27. Kim CH, Hyun Song M, Eun Ahn Y, Lee JG, Yoon JH (2005) Effect of hypoiso- and hypertonic saline irrigation on secretory mucins and morphology of cultured human nasal epithelial cells. Acta Otolaryngol 125: 1296-1300.

28. Hermelingmeier KE, Weber RK, Hellmich M, Heubach CP, Mösges R (2012) Nasal irrigation as an adjunctive treatment in allergic rhinitis: a systematic review and meta-analysis. Am J Rhinol Allergy 26: e119-125. 